\title{
Flavonoid Composition of Salacia senegalensis (Lam.) DC. Leaves, Evaluation of Antidermatophytic Effects, and Potential Amelioration of the Associated Inflammatory Response
}

\author{
Nelson G. M. Gomes ${ }^{1}$, Andreia P. Oliveira ${ }^{1}$, Diana Cunha ${ }^{2}$, David M. Pereira ${ }^{1}$, \\ Patrícia Valentão ${ }^{1}$ D , Eugénia Pinto ${ }^{2,3}{ }^{D}$, Luísa Araújo ${ }^{4}$ and Paula B. Andrade ${ }^{1, *(D)}$ \\ 1 REQUIMTE/LAQV, Laboratório de Farmacognosia, Departamento de Química, Faculdade de Farmácia, \\ Universidade do Porto, R. Jorge Viterbo Ferreira, n² 228, 4050-313 Porto, Portugal \\ 2 Laboratório de Microbiologia, Departamento de Ciências Biológicas, Faculdade de Farmácia, \\ Universidade do Porto, R. Jorge Viterbo Ferreira, n 228, 4050-313 Porto, Portugal \\ 3 Centro Interdisciplinar de Investigação Marinha e Ambiental (CIIMAR/CIMAR), Universidade do Porto, \\ Edifício do Terminal de Cruzeiros do Porto de Leixões, Av. General Norton de Matos s/n, \\ 4450-208 Matosinhos, Portugal \\ 4 MDS-Medicamentos e Diagnósticos em Saúde, Avenida dos Combatentes da Liberdade da Pátria, \\ Bissau, Guiné-Bissau \\ * Correspondence: pandrade@ff.up.pt; Tel.: +351-220-428-654
}

Received: 17 June 2019; Accepted: 9 July 2019; Published: 10 July 2019

\begin{abstract}
Predominantly spread in West Tropical Africa, the shrub Salacia senegalensis (Lam.) DC. is known because of its medicinal properties, the leaves being used in the treatment of skin diseases. Prompted by the ethnomedicinal use, a hydroethanolic extract obtained from the leaves of the plant was screened against a panel of microbial strains, the majority of which involved in superficial infections. The extract was found to be active against the dermatophytes Trichophyton rubrum and Epidermophyton floccosum. Notable results were also recorded regarding the attenuation of the inflammatory response, namely the inhibitory effects observed against soybean 5-lipoxygenase $\left(\mathrm{IC}_{50}=71.14 \mu \mathrm{g} \mathrm{mL}{ }^{-1}\right)$, no interference being recorded in the cellular viability of RAW 264.7 macrophages and NO levels. Relevantly, the extract did not lead to detrimental effects against the keratinocyte cell line $\mathrm{HaCaT}$, at concentrations displaying antidermatophytic and anti-inflammatory effects. Flavonoid profiling of $S$. senegalensis leaves was achieved for the first time, allowing the identification and quantitation of myricitrin, three 3-O-substituted quercetin derivatives, and three other flavonoid derivatives, which may contribute, at least partially, to the observed antidermatophytic and anti-inflammatory effects. In the current study, the plant $S$. senegalensis is assessed concerning its antidermatophytic and anti-inflammatory properties.
\end{abstract}

Keywords: antifungal; flavonoids; inflammation; Isoquercitrin; Myricetin-3-O-rhamnoside; Quercetin-3-Oxyloside; Quercitrin; traditional medicine

\section{Introduction}

As part of our ongoing research program on plants from the Afrotropical realm [1-3], the antimicrobial properties of Salacia senegalensis (Lam.) DC. were investigated; this involved being subjected to a phytochemical study. Commonly known in Guinea-Bissau as "mancuba" or "mancúbaru", S. senegalensis (Celastraceae) is a shrub which is widely spread in West Tropical Africa, particularly in Guinea-Bissau, Senegal, and Guinea [4]. Predominantly known for its antimalarial effects, extracts from the leaves are also reported to be used in the treatment of skin malignancies in Guinea and Nigeria [5-7]. 
Prior meta-analyses demonstrated a higher hit rate for antifungal activity with plants recorded for their ethnomedicinal use in the treatment of skin infections with an obvious pathological expression, in comparison with "random" collection [8]. Consequently, a hydroethanolic extract obtained from the leaves of S. senegalesis was selected and evaluated for its efficacy against a panel of fungi responsible for superficial infections. As a result of their high incidence, the panel also included fungal strains involved in systemic infections and the bacterial pathogens Staphylococcus aureus and Escherichia coli. This study was also motivated by the increasing incidence of skin microbial infections [9]. For example, dermatophytes affect $20-25 \%$ of the world population, with non-dermatophyte molds and yeasts further contributing to a public health problem related with skin pathogens, which translates into an economic burden $[9,10]$. While Candida albicans is the most common opportunistic human fungal pathogen [10], tinea pedis and onychomycosis are becoming an epidemiological problem, the anthropophilic species Trichophyton rubrum being the main etiological agent worldwide [9].

The assessment of the antimicrobial effects upon exposure to the extract obtained from the leaves of S. senegalensis was followed by assays geared towards the evaluation of its interference with RAW 264.7 macrophages and the enzymatic activity of the eicosanoid-metabolizing enzyme 5-lipoxygenase (5-LOX). Macrophages are one of the pivotal elements in the control of dermatomycotic infections, being involved in the microcidal effects, particularly through the production of reactive oxygen species (ROS) and reactive nitrogen species (RNS) [9,11]. While RNS appear not to be involved in the inflammatory response to specific fungal infections, such as dermatophytic ones, most skin pathogens are keratinophilic (i.e., produce keratinolytic enzymes) and are responsible for inducing an inflammatory reaction at the site of the infection [12]. Particularly concerning common dermatomycotic agents, the stepwise process of host infection is similar among most of the dermatophytes, as well as Candida spp. and Malassezia spp., including an inflammatory response mediated by eicosanoid-metabolizing enzymes [9,12].

As reviewed by Bagnazari et al. [13], several Salacia spp. have been reported to display relevant biological properties, namely antioxidant, anti-inflammatory, and antimicrobial activities; it is worth highlighting the antidiabetic properties of the Ayurvedic herbal medicine Salacia reticulata attributed to the highly potent $\alpha$-glucosidase inhibitor salacinol and related sulfonium-ion inhibitors $[14,15]$. As there are only a few studies dealing with the biological properties of $S$. senegalesis, in the current study we mainly aimed to evaluate the potential of its leaves on the treatment of skin infections. As such, the hydroethanolic extract obtained from the plant was evaluated for its antimicrobial effects as well as its potential interference with pivotal targets that mediate the inflammatory response derived from cutaneous infection. Cytotoxicity against the skin cell model HaCaT cells was also investigated.

\section{Results and Discussion}

\subsection{Characterization of the Flavonoid Profile of S. senegalensis Leaves}

While being a species widely distributed in West Tropical Africa, reports on the chemical profile of S. senegalensis are scant. Previous studies on the leaves of the plant include the analysis of the proximate, vitamin and mineral composition [6], and the chemical profiling of its essential oil [5]. Adumanya [16] reported a series of phenolic acids in leaves from S. senegalensis obtained from an undefined location, details on the preparation of the extracts and chromatographic conditions also being absent. As such, because of the paucity of information on the metabolic versatility of the plant, the chemical profile of the leaves was investigated. Comparison with authentic substances did not allow us to identify any of the previously reported phenolic acids on the hydroethanolic extract obtained from the leaves of $S$. senegalensis under study. On the other hand, HPLC-DAD analysis allowed the identification and quantitation of several flavonoids: myricetin-3-O-rhamnoside (myricitrin; 1 ), three quercetin derivatives $(\mathbf{3}, \mathbf{6}$, and $\mathbf{7})$, and other flavonoids (2, 4, and 5) (Figure 1 and Table 1). Comparison with authentic standards allowed us to unequivocally ascribe $\mathbf{1}$ as myricitrin, as well as $\mathbf{3 , 6}$, and $\mathbf{7}$ as the 
mono-O-glycosyl quercetin derivatives quercetin-3-O-glucoside (isoquercitrin), quercetin-3-O-xyloside, and quercetin-3-O-rhamnoside (quercitrin), respectively (Figure 2).

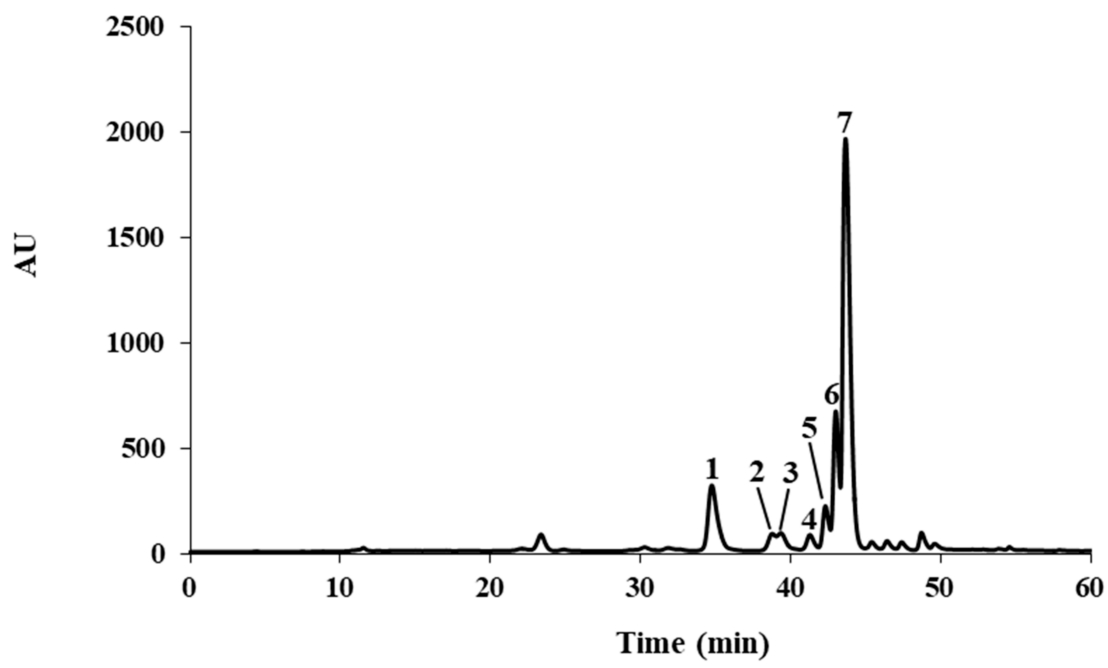

Figure 1. HPLC-UV $(350 \mathrm{~nm})$ profile of the hydroethanolic extract from Salacia senegalensis leaves. Identity of compounds 1-7 as in Table 1 and text.

The UV spectra exhibited by compounds 2,4 , and 5 clearly indicated that they are flavonoid derivatives, namely 3-O-substituted quercetin derivatives (Table 1 ), characterized by a hypsochromic shift of $c a .20 \mathrm{~nm}(372 \rightarrow 355)$ in band I and a reduction in intensity relative to band II, in comparison with the aglycone quercetin ( $\lambda \max 255,295 \mathrm{sh}$ and $372 \mathrm{~nm}$ ) [17]. Therefore, considering the UV data and the presence of other quercetin derivatives, these compounds are also probably quercetin glycosides.

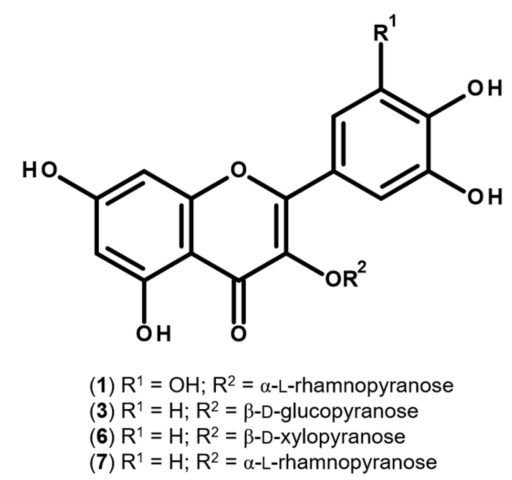

Figure 2. Structure of myricitrin (1), and quercetin 3-O-glycosides isoquercitrin (3), quercetin-3-Oxyloside (6) and quercitrin (7).

Quantitatively, the hydroethanolic extract obtained from S. senegalensis leaves was found to be rich in flavonoids, exhibiting a high content of quercetin derivatives (81.8\%), quercitrin (7) being identified as the main constituent (68.6\%), followed by myricitrin (1), constituting ca. $12.7 \%$ of the determined flavonoids (Table 1). 
Table 1. Content of flavonoids in the hydroethanolic extract of S. senegalensis leaves.

\begin{tabular}{|c|c|c|c|}
\hline Peak & Compounds & UV (nm) & $\mathrm{mg} \mathrm{Kg}^{-1}$ Dry Extract \\
\hline 1 & Myricitrin & 259,298 sh, 351 & $10165.70 \pm 119.98$ \\
\hline 2 & Flavonoid derivative & $257,266 \mathrm{sh}, 355$ & $916.35 \pm 85.12$ \\
\hline 3 & Isoquercitrin & 257,266 sh, 353 & $1096.10 \pm 48.29$ \\
\hline 4 & Flavonoid derivative & $257,267 \mathrm{sh}, 355$ & $731.05 \pm 38.75$ \\
\hline 5 & Flavonoid derivative & $256,266 \mathrm{sh}, 294 \mathrm{sh}, 354$ & $2741.27 \pm 113.18$ \\
\hline 6 & Quercetin-3-O-xyloside & $256,265 \mathrm{sh}, 294 \mathrm{sh}, 354$ & $9424.36 \pm 213.32$ \\
\hline 7 & Quercitrin & $260,306 s h, 352$ & $54675.24 \pm 1352.64$ \\
\hline \multicolumn{3}{|c|}{ Total } & $79750.07 \pm 1971.28$ \\
\hline
\end{tabular}

\subsection{Antimicrobial Effects}

While predominantly known for their antidiabetic properties, several species belonging to the genus Salacia have been reported to display antimicrobial properties, particularly against bacterial pathogens [18-20]. In contrast, reports on the antidermatophytic effects are restricted to a study with an ethanolic extract obtained from the bark of Salacia crassifolia, proving to be active against T. rubrum and Trichophyton mentagrophytes [21].

As in Svetaz et al. [8] and following a standardized definition of "active" extracts, only minimum inhibitory concentration (MIC) values $\leq 1 \mathrm{mg} \mathrm{mL}^{-1}$ were considered relevant. As seen in Table 2, the hydroethanolic extract obtained from the leaves of S. senegalensis was found to be active against the anthropophilic dermatophytes T. rubrum and Epidermophyton floccosum (MIC $=1 \mathrm{mg} \mathrm{mL}^{-1}$ ), proving it to be a fungicidal agent, exhibiting minimum lethal concentration (MLC) values of 2 and $4 \mathrm{mg} \mathrm{mL}^{-1}$, respectively. It is also worth noting the moderate fungistatic effects ( $\mathrm{MIC}=2 \mathrm{mg} \mathrm{mL}^{-1}$ ) against the zoophilic dermatophytes Microsporum canis and T. mentagrophytes, while it was less effective against the geophilic Microsporum gypseum (MIC $=4 \mathrm{mg} \mathrm{mL}^{-1}$ ) (Table 2). The extract, at $4 \mathrm{mg} \mathrm{mL}^{-1}$, was unable to exert fungistatic/fungicidal effects against the remaining human pathogenic fungi (Table 2). Although without relevant antibacterial effects (Table 2), a bacteriostatic effect was observed for S. aureus at $2 \mathrm{mg}$ $\mathrm{mL}^{-1}$, a species frequently associated with dermatophytes in superficial infections [22].

While commonly mimicking other clinical conditions [12], the most common dermatophyte-derived lesions exhibit evident clinical signals, characterized as circular and erythematous, being easily detected and followed by traditional healers [8]. Curiously, the hydroethanolic extract obtained from the leaves of $S$. senegalensis was found to be solely active against causal agents related to skin or mucosal infections characterized by an evident and visible pathological expression, such as the dermatophytes T. rubrum and E. floccosum, while being devoid of notable fungicidal or fungistatic effects against yeasts or Aspergillus fumigatus (Table 2).

Flavonoids have been reported as a privileged class of antifungal agents due to their ability to interfere with several cellular targets [23]. Flavonols, in particular, have received the most attention due to the wide spectrum of associated antifungal effects, as well as their ability to suppress a number of fungal virulence factors $[23,24]$. Previous reports on the fungitoxic effects of isoquercitrin (3) evidenced a strong fungistatic effect against a strain of T. rubrum obtained from the Korean Collection for Type Cultures (KCTC), with a MIC value of $2.5 \mu \mathrm{g} \mathrm{mL}^{-1}$ [25]. Relevantly, structure-activity relationship (SAR) studies revealed that flavonoids with free C-5 and C-7 hydroxyl groups in ring A, such as those found in the extract under study (Table 1 and Figure 2), tend to be particularly active against T. rubrum [26]. Since there are no reports on the effect of myricitrin (1) and quercitrin (7) against T. rubrum, both flavonols were individually assessed at concentrations as high as 50 and $200 \mu \mathrm{gL}^{-1}$, respectively. No noticeable fungitoxicity was observed. However, exposure to a mixture of myricitrin (1) and quercitrin (7) at concentrations of 10 and $55 \mu \mathrm{g} \mathrm{mL}^{-1}$ (corresponding to the MIC value recorded upon treatment with $S$. senegalensis leaf extract) led to weak inhibitory effects $(<50 \%)$ against T. rubrum. As such, it is plausible to consider that the fungistatic effect observed against T. rubrum upon treatment with the extract under study (Table 2) may be partially related with a synergistic or additive effect between the identified flavonols. 
Table 2. Antimicrobial effects upon exposure to the hydroethanolic extract obtained from the leaves of S. senegalensis against human pathogenic fungi and bacteria.

\begin{tabular}{ccc}
\hline Microorganism & MIC $^{\mathbf{a}}$ & MLC $^{\mathbf{b}}$ \\
\hline Fungi & & \\
Candida albicans ATCC ${ }^{\circledR} 10231$ & $>4$ & $>4$ \\
Candida albicans D5 & $>4$ & $>4$ \\
Malassezia furfur P26 & 4 & $>4$ \\
Aspergillus fumigatus ATCC ${ }^{\circledR}$ 204305 & $>4$ & $>4$ \\
Scopulariopsis brevicaulis FF & $>4$ & $>4$ \\
Epidermophyton floccosum FF9 & 1 & 4 \\
Microsporum canis FF1 & 2 & 4 \\
Microsporum gypseum FF3 & 4 & $>4$ \\
Trichophyton mentagrophytes FF7 & 2 & 4 \\
Trichophyton rubrum FF5 & 1 & 2 \\
\hline Bacteria & & \\
Escherichia coli ATCC ${ }^{\circledR}$ 25922 & $>4$ & $>4$ \\
Staphylococcus aureus ATCC ${ }^{\circledR} 25923$ & 2 & $>4$ \\
\hline
\end{tabular}

${ }^{a}$ MIC - minimum inhibitory concentration; ${ }^{b}$ MLC - minimum lethal concentration. MIC and MLC values expressed in $\mathrm{mg} \mathrm{mL}^{-1}$.

Concerning the inhibitory effects against the dermatophyte E. floccosum, to the best of our knowledge, there are no reports on the fungitoxic effects of the flavonols identified in the S. senegalensis leaf extract. Similarly to what has been observed against T. rubrum, while none of the main components (1 and 7) identified in the extract were active against $E$. floccosum, a noticeable fungitoxic effect was observed upon exposure to a mixture of myricitrin (1) and quercitrin (7) at 10 and $55 \mu \mathrm{gL} \mathrm{m}^{-1}$, respectively.

\subsection{Inhibitory Effects Against 5-Lipoxygenase Activity}

The inflammatory response triggered by the presence of the fungus or the release of its metabolites and virulence factors play a relevant role in tissue damage during fungal infection [12,27]. In contrast to pathogenic yeasts, such as C. albicans, which generally leads to a low inflammatory response, dermatophytes frequently induce a significant level of inflammation and tissue damage [12]. The signs and symptoms elicited by inflammation, such as erythema, burning, or pruritus, are associated with most dermatomycotic infections [12]. While 5-LOX metabolism does not seem to play a key role in normal epithelial homeostasis, leukotrienes have long been associated with several inflammatory skin disorders [28,29]. 5-LOX from epidermal keratinocytes is involved in the production of the potent itch mediator leukotriene $\mathrm{B}_{4}\left(\mathrm{LTB}_{4}\right)$, being closely associated with dermatophyte-derived pruritus, the most common functional symptom of dermatophytosis [28]. In fact, the anti-inflammatory effects of conventional antifungal agents, such as several azoles, occur via the inhibition of 5-LOX, through the blockage of $\mathrm{LTB}_{4}$ synthesis in the skin [30].

Most structural research on the pharmacological interruption of the 5-LOX pathway has been done on soybean 5-LOX due to the lack of sufficiently purified human isoform (this is also due to the similarity between the active sites of human and soybean 5-LOX) [31]. In fact, the homology between human and soybean 5-LOX has long been known, as evidenced by cDNA sequencing [31,32]. Since the stereo- and regiospecific catalyzed incorporation of molecular oxygen into polyunsaturated fatty acids containing a (cis,cis)-1,4-pentadiene system is common between different isoforms of the enzyme [33], 5-LOX from Glycine max was used to evaluate the inhibitory effects of the $S$. senegalensis leaf extract. While displaying a lower inhibitory potency than the reference inhibitor quercetin $\left(\mathrm{IC}_{50}=8.40 \mu \mathrm{g}\right.$ $\mathrm{mL}^{-1}$ ), a significant concentration-dependent inhibition of 5-LOX was observed at concentrations ranging from 15.17 to $242.58 \mu \mathrm{g} \mathrm{mL}^{-1}(p<0.05)$ : an $\mathrm{IC}_{50}$ value of $71.14 \mu \mathrm{g} \mathrm{mL} \mathrm{m}^{-1}$ was recorded (Figure 3).

In order to investigate if the observed inhibitory effects were related with the flavonols identified in the extract (Table 1 and Figure 2), the main components, myricitrin (1) and quercitrin (7), were evaluated for 5-LOX inhibition at concentrations corresponding to the $\mathrm{IC}_{50}$ value and the highest concentration of the extract. At the highest concentrations tested, both myricitrin (1) and 
quercitrin (7) were able to significantly inhibit the enzymatic activity of 5-LOX $(p<0.01)$ at 2.47 and $13.26 \mu \mathrm{g} \mathrm{mL}^{-1}$, down to 87.6 and $82.8 \%$, respectively. However, at the concentrations corresponding to the $\mathrm{IC}_{50}$ value calculated after exposure to the extract obtained of $S$. senegalensis leaves, only 7 proved to be active, leading to a significant inhibitory effect $(p<0.01)$ at $3.89 \mu \mathrm{g} \mathrm{mL}^{-1}(8.68 \mu \mathrm{M})$, with $12.4 \%$ of inhibition. Our data corroborate previous findings on the inhibitory effects of both flavonols against 5-LOX [34,35]. In fact, not only the main components $\mathbf{1}$ and $\mathbf{7}$ have been previously reported as 5-LOX inhibitors, but also other flavonol derivatives identified on the hydroethanolic extract obtained from the leaves of $S$. senegalensis (Table 1 and Figure 2). Using the same in vitro model, Kim et al. [36] reported the inhibitory effects of isoquercitrin (3) and quercetin-3-O-xyloside (6) on 5-LOX, exhibiting $\mathrm{IC}_{50}$ values of 40.1 and $32.9 \mu \mathrm{M}$, respectively.

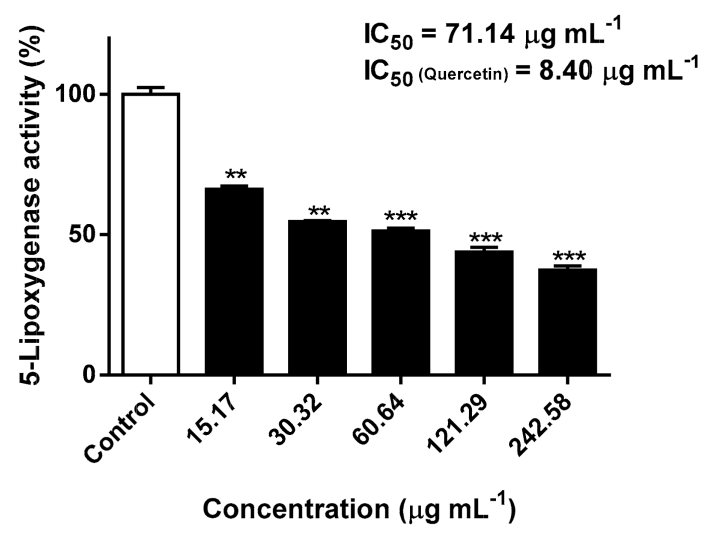

Figure 3. Inhibitory effects against 5-lipoxygenase (5-LOX) activity upon exposure to S. senegalensis leaf hydroethanolic extract. The results correspond to the mean \pm SEM of three independent experiments performed in triplicate (statistical significance: ${ }^{* *} p<0.01$ and ${ }^{* *} p<0.001$ ).

From these data, it is plausible to deduce a relationship between the flavonol content of the hydroethanolic extract from S. senegalensis leaves and the inhibitory effects on 5-LOX. In fact, SAR studies suggest that the flavonol series, particularly myricetin and quercetin derivatives, is a privileged group for the inhibition of the enzyme due to their chemical scaffolds $[33,37]$. Comparison between a series of structural analogues evidenced that pivotal features for the inhibition of 5-LOX include the presence of the 2,3-double bond with a 4-oxo functionality in the C-ring, since it completes a conjugated binding system through all the ring, thus stabilizing complexes or radical intermediates [33]. Furthermore, it confers planarity, allowing a more readily intercalation between aromatic or heteroaromatic amino acid residues at the active site of the enzyme [33,38]. Relevantly, it has been previously reported that the fully planar structure is best realized with quercetin and its derivatives [38]. SAR studies also denote the substantial importance of a catecholic arrangement in ring B, as the 3'4'-vicinal diol grouping confers a high stability to the radical form and participates in electron delocalization [33]. Finally, glycosylation at position C-3 greatly lessens the inhibitory effect, suggesting that the higher hydrophilicity restrains the intercalation in the lipophilic active site of LOXs [37,38].

The observed inhibitory effects are particularly relevant in dermatophytic infections, since both 5-LOX from the host epidermal keratinocytes and from the dermatophyte can be targeted. Dermatophytes display the ability for both de novo and "trans-species" production of leukotrienes via LOX during infection, enhancing the acute inflammatory response, a possible link between leukotriene production and fungal growth being also reported [39].

Relevantly, while the poor bioavailability and rapid metabolism of flavonoids has been associated with weak efficacy after oral administration, the facilitated skin penetration and high potency as inhibitors of 5-LOX suggests their potential use against superficial inflammatory conditions [40]. 


\subsection{Effects Against RAW 264.7 Cells' Viability and NO Levels}

While the exact sequence of events involved in the immunologic defense against dermatophytes is not clearly defined yet, macrophages constitute a prominent element of antidermatophyte defenses, inducing the activation of an adaptative response to control the infection [9]. Upon infection by dermatophytes, the secretion of several cytokines by macrophages is increased, oxidative burst leading to an augmented secretion of RNS and ROS in activated macrophages [9]. Generally, the immune defense against mycotic agents partially depends upon the oxidative killing involving ROS and RNS [11]. In fact, nitrosative stress plays a preponderant and beneficial role in the antifungal effect against T. rubrum, an increased production of NO being related with the antidermatophytic effect [41].

Since the extract obtained from the leaves of $S$. senegalensis was found to be particularly active against dermatophytic strains, the potential hazardous interference with the mitochondrial viability of RAW 264.7 macrophages and NO levels was investigated. RAW 264.7 cells were incubated with increasing concentrations of $S$. senegalensis leaf extract, no significant effects being observed up to concentrations as high as the MIC value $\left(1 \mathrm{mg} \mathrm{mL}^{-1}\right)$ (Figure $\left.4 \mathrm{~A}\right)$. The potential interference of S. senegalensis leaf extract on lipopolyssacharide (LPS)-induced production of NO in RAW 264.7 cells was evaluated at concentrations $\leq 1 \mathrm{mg} \mathrm{mL}^{-1}$, through a mainstay cell-based in vitro assay based on the Griess method. As seen in Figure 4B, pre-treatment with the extract did not cause any notable effect on NO levels, being innocuous and conveniently not interfering in the production of the preponderant RNS mediator of the antidermatophytic response.

A

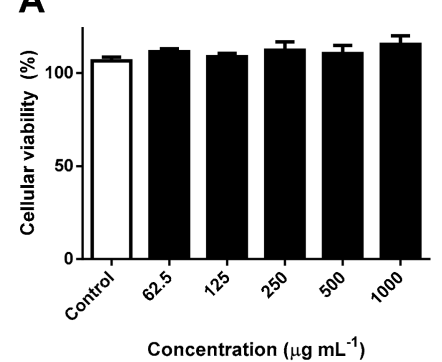

B

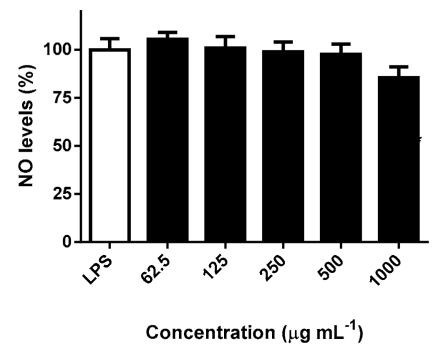

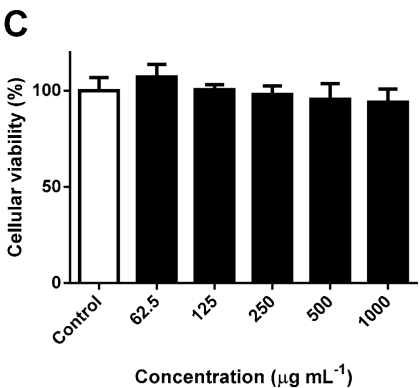

Figure 4. Effects of S. senegalensis leaf hydroethanolic extract on the cellular viability of (A) RAW 264.7 macrophages, (B) interference with NO levels in LPS-stimulated RAW 264.7 macrophages, and (C) on the cellular viability of $\mathrm{HaCaT}$ keratinocytes. The results correspond to the mean $\pm \mathrm{SEM}$ of three independent experiments performed in triplicate.

\subsection{Effects Against HaCaT Cells' Viability}

Being the most common cell type of the human epidermis, keratinocytes are the first line of defense against microbial pathogens and other external agents, contributing to the regulation of a variety of physiological and pathological processes [42,43]. In fact, keratinocytes not only act as a building block of the skin but play also an active part in immune response, inflammatory processes, and wound healing, being involved in an interplay with various dermal immunocompetent cells [43].

Appropriate cell lines to assess skin biocompatibility and cytotoxicity include human epidermal keratinocytes, monolayer cultures of $\mathrm{HaCaT}$ cells being one of the most conventional in vitro models to address topical safety [44]. The cytotoxicity of the hydroethanolic extract obtained from the leaves of S. senegalensis was evaluated for $24 \mathrm{~h}$, no significant interference on the cellular viability of $\mathrm{HaCaT}$ cells being noted at concentrations ranging from 62.5 to $1000 \mu \mathrm{g} \mathrm{mL}^{-1}$ (Figure 4C). Such results indicate that the extract has a safe toxicological profile against epidermal keratinocytes at concentrations displaying antidermatophytic and anti-inflammatory effects. 


\section{Materials and Methods}

\subsection{Plant Material and Extraction}

Leaves from S. senegalensis (Lam.) DC., growing in Ilha Formosa, Guinea-Bissau, were collected in April 2017. The plant name was checked with The Plant List (http://www.theplantlist.org/tp11.1/ record/kew-2481214?ref=tpl1; accessed January 28, 2019). A voucher specimen of the leaves (GB72) was deposited at the Laboratory of Pharmacognosy, Faculty of Pharmacy, University of Porto. Samples were air-dried, ground to fine powder (mean particle size $\leq 910 \mu \mathrm{m}$ ), the hydroethanolic extract being obtained through maceration of $c a .6 \mathrm{~g}$ of the powdered material with $500 \mathrm{~mL}$ of a mixture of ethanol (Fischer Scientific, Loughborough, UK) and water (4:1), under magnetic stirring (450 rpm) for $30 \mathrm{~min}$. The resulting extract was filtered through Whatman ${ }^{\circledR}$ grade 1 filtration paper (Sigma-Aldrich, St. Louis, MO, USA), concentrated to dryness under reduced pressure in a Büchi Labortechnik AG Rotavapor $^{\circledR}$ R-215 (Flawil, Switzerland), and kept at $-20{ }^{\circ} \mathrm{C}$, in the dark, until analysis. The extraction yield was $21.12 \%$.

\subsection{HPLC-DAD Characterization of S. senegalensis Leaf Hydroethanolic Extract}

The hydroethanolic extract was analyzed on an analytical HPLC unit (Gilson Medical Electronics, Villiers le Bel, France), using a $250 \times 4.6 \mathrm{~mm}, 5 \mu \mathrm{m}$, Spherisorb ODS2 $80 \AA$ RP-C18 column (Waters, Dublin, Ireland). The dried residue $\left(50 \mathrm{mg} \mathrm{mL}^{-1}\right)$ was redissolved in methanol LiChrosolv ${ }^{\circledR}$ (Merck KGaA, Darmstadt, Germany), filtered through a $0.45 \mu \mathrm{M}$ pore size polytetrafluoroethylene (PTFE) membrane (Millipore, Bedford, MA, USA), and analyzed in triplicate. The mobile phase consisted of two solvents: $\mathrm{HCOOH} \mathrm{5 \%} \mathrm{(A)} \mathrm{and} \mathrm{methanol} \mathrm{(B),} \mathrm{starting} \mathrm{with} \mathrm{5 \%} \mathrm{B} \mathrm{and} \mathrm{using} \mathrm{a} \mathrm{gradient} \mathrm{to} \mathrm{obtain}$ $15 \% \mathrm{~B}$ at $3 \mathrm{~min}, 25 \% \mathrm{~B}$ at $13 \mathrm{~min}, 30 \% \mathrm{~B}$ at $25 \mathrm{~min}, 35 \% \mathrm{~B}$ at $35 \mathrm{~min}, 45 \% \mathrm{~B}$ at $39 \mathrm{~min}, 45 \% \mathrm{~B}$ at $42 \mathrm{~min}, 55 \% \mathrm{~B}$ at $47 \mathrm{~min}, 75 \% \mathrm{~B}$ at $56 \mathrm{~min}$, and $100 \% \mathrm{~B}$ at $60 \mathrm{~min}$. The flow rate was $0.9 \mathrm{~mL} \mathrm{~min}^{-1}$. Detection was achieved with an Agilent 1100 series diode array detector (DAD) (Agilent Technologies, Waldbronn, Germany). Spectral data from all peaks were accumulated in the range 200-700 nm and chromatograms were recorded at $350 \mathrm{~nm}$. Quantitative analysis was performed using external calibration curves (Table 3), using the equation of linear regression (concentration vs. optical absorbance at $350 \mathrm{~nm}$ ) of each standard.

Calibration curves were built with five concentrations of each standard and analyzed in triplicate, according to the range of concentrations found in the hydroethanolic extract. Myricitrin (1), isoquercitrin (3), and quercitrin (7) were quantitated against their own standard curves, compounds 2, 4-6 being also quantitated as isoquercitrin (3). The phytochemical standards isoquercitrin, myricitrin, quercitrin, and quercetin-3-O-xyloside were purchased from Extrasynthese (Genay, France). Linearity was evaluated from the coefficients of determination $\left(R^{2}\right)$ of the regression curves; limits of detection (LOD) and quantification (LOQ) were determined from the residual standard deviation $(\sigma)$ of the curves and the slopes $(S)$ : $\mathrm{LOD}=3.3 \sigma / S$ and $\mathrm{LOQ}=10 \sigma / S$. Data were processed on the Clarity software system, version 5.04.158 (DataApex Ltd., Prague, Czech Republic).

Table 3. Linear regression equation analysis, $\mathrm{LOD}^{\mathrm{a}}$ and $\mathrm{LOQ}^{\mathrm{b}}$, for external standards.

\begin{tabular}{|c|c|c|c|c|c|c|}
\hline \multirow[b]{2}{*}{ Standard } & \multicolumn{3}{|c|}{ Regression Equation } & \multirow{2}{*}{$\begin{array}{c}\text { Linearity } \\
\text { Range } \\
\left(\mu \mathrm{g} \mathrm{mL}^{-1}\right)\end{array}$} & \multirow{2}{*}{$\begin{array}{c}\text { LOD } \\
\left(\mu \mathrm{g} \mathrm{mL}^{-1}\right)\end{array}$} & \multirow{2}{*}{$\begin{array}{c}\mathrm{LOQ} \\
\left(\mu \mathrm{g} \mathrm{mL^{-1 } )}\right.\end{array}$} \\
\hline & $\begin{array}{c}\text { Slope } \\
(S)\end{array}$ & $\begin{array}{l}\text { Intercept } \\
(\text { b })\end{array}$ & $\begin{array}{c}R^{2} \\
(\mathrm{n}=3)\end{array}$ & & & \\
\hline Myricitrin & 44.893 & 831.50 & 0.998 & $25-400$ & 4.78 & 14.49 \\
\hline Isoquercitrin & 59.725 & 694.77 & 0.996 & $12.5-200$ & 0.507 & 1.537 \\
\hline Quercitrin & 48.9 & 1085.9 & 0.997 & $25-400$ & 0.591 & 1.792 \\
\hline
\end{tabular}

${ }^{\mathrm{a}} \mathrm{LOD}=$ Limit of detection; ${ }^{\mathrm{b}} \mathrm{LOQ}=$ limit of quantification. 


\subsection{Antimicrobial Activity Evaluation}

\subsubsection{Microbial Strains and Media}

The antifungal activity was evaluated against ten fungal strains: three yeasts (C. albicans ATCC ${ }^{\circledR}$ 10231, a fluconazole-resistant C. albicans clinical isolate D5, Malassezia furfur clinical isolate P26 and seven filamentous fungi (A. fumigatus ATCC ${ }^{\circledR}$ 204305, Scopulariopsis brevicaulis clinical isolate FF and five clinical dermatophyte strains T. rubrum FF5, T. mentagrophytes FF7, M. canis FF1, M. gypseum FF3, and E. floccosum FF9). Clinical isolates were obtained from a recurrent case of oral candidosis (C. albicans D5), from nails and skin (dermatophytes, S. brevicaulis FF and M. furfur P26), identified by Prof. Dr. Eugénia Pinto (Laboratory of Microbiology, Faculty of Pharmacy, University of Porto). Candida krusei ATCC ${ }^{\circledR} 6258$ was used for quality control. The antibacterial potential was evaluated against Gram-negative bacteria (E. coli ATCC ${ }^{\circledR}$ 25922) and Gram-positive bacteria (S. aureus ATCC $^{\circledR 2}$ 25923).

To guarantee the purity, viability, and optimal growth, all strains were sub-cultured before each assay: C. albicans, A. fumigatus, and S. brevicaulis on Sabouraud dextrose agar (SDA, bioMérieux, Marcy l'Etoile, France) and incubated at $35^{\circ} \mathrm{C}$ for $24 \mathrm{~h}, 48 \mathrm{~h}$, and 4 days, respectively; $M$. furfur on SDA with $2 \%$ of tween (TW) 80 was incubated for 3 days at $35^{\circ} \mathrm{C}$; dermatophytes on Mycosel agar (MYC, Becton Dickinson, Sparks, MD, USA) were incubated for 5-7 days at $25^{\circ} \mathrm{C}$; S. aureus and E. coli on Mueller-Hinton agar (MHA, Liofilchem, Roseto degli Abruzzi, Italy) were incubated for $24 \mathrm{~h}$, at $35{ }^{\circ} \mathrm{C}$. RPMI-1640 broth medium, with L-glutamine and without $\mathrm{NaHCO}_{3}$ (Biochrom $\mathrm{GmbH}$, Berlin, Germany), used on the evaluation of antifungal activity, was buffered with $0.165 \mathrm{~mol}$ $\mathrm{L}^{-1}$ of 3-(N-morpholino)-propanesulfonic acid (MOPS, Sigma-Aldrich, St. Louis, MO, USA), pH being adjusted to $7.0 \pm 0.2$ with $1 \mathrm{~mol} \mathrm{~L}^{-1} \mathrm{NaOH}$. For $M$. furfur, $\%$ of TW80 was added to RPMI. Mueller-Hinton broth 2 (MHB2, Becton Dickinson, Sparks, MD, USA) was used for the evaluation of antibacterial activity.

\subsubsection{Antimicrobial Susceptibility Testing by Broth Microdilution}

The minimum inhibitory concentrations (MICs) and minimal lethal concentrations (MLCs) were used for determining the antimicrobial activity in agreement with the recommendations of the Clinical and Laboratory Standards Institute (CLSI) reference documents, with minor modifications: M27-A3 [45] and M38-A2 [46] for yeasts and filamentous fungi, respectively; M100-A25 [47] for bacteria.

A $100 \mathrm{mg} \mathrm{mL}^{-1}$ solution of the extract was prepared in dimethylsulfoxide (DMSO, Sigma-Aldrich, St. Louis, MO, USA). Two-fold serial dilutions were prepared within the concentration range $0.25-4 \mathrm{mg}$ $\mathrm{mL}^{-1}$, in MHB2 for bacteria and RPMI for fungi, no interference of DMSO on the bacterial/fungal growth being noted. Sterile and disposable microtiter plates, with 96 flat bottom wells, were used to evaluate the susceptibility of the microorganisms to the sample. Equal volumes of cell suspension and sample dilutions were added in the wells.

Three controls were performed: a sterility control, a growth control, and a quality control, performed with an ATCC ${ }^{\circledR}$ reference strain, gentamicin (Sigma-Aldrich, Seelze, Germany) and voriconazole (kindly provided by Pfizer, Main St., Cambridge, MA, USA) being used as reference antibacterial and antifungal agents, respectively.

The hydroethanolic extract and compounds were tested in duplicate and independently at least three times.

\section{Antibacterial Susceptibility Testing}

Cell suspensions were prepared from pure cultures on $\mathrm{MHA} / 24 \mathrm{~h}$ in a sterile saline solution, adjusted to obtain a MacFarland standard of 0.5 at $530 \mathrm{~nm}$, corresponding to $1-5 \times 10^{6} \mathrm{cells}_{\mathrm{mL}}^{-1}$. This initial suspension was diluted in MHB2 to obtain an inoculum suspension of $1-5 \times 10^{4} \mathrm{CFU} \mathrm{mL}^{-1}$. Gentamicine $\left(0.06-4 \mu \mathrm{g} \mathrm{mL}{ }^{-1}\right.$ ) was used as a quality control, with E. coli ATCC ${ }^{\circledR} 25922$, the obtained results being within the recommended limits defined by CLSI protocols; a MIC value of $0.5 \mathrm{mg} \mathrm{L}^{-1}$ 
was determined. The plates were incubated aerobically at $35^{\circ} \mathrm{C}$ for $24 \mathrm{~h}$. The MIC was determined as the lowest concentration at which no visible growth was observed. The MLC was assessed by spreading $10 \mu \mathrm{L}$ of culture collected from wells showing no visible growth on MHA plates. The MLC was determined as the lowest concentration at which no colonies grew after $16-18 \mathrm{~h}$ incubation at $35^{\circ} \mathrm{C}$.

\section{Antifungal Susceptibility Testing}

Yeast cells suspensions were prepared from pure cultures on SDA/24 h, or SAB + TW80/3 days, in sterile saline solution and adjusted to MacFarland standard of 0.5 at $530 \mathrm{~nm}$, corresponding to an initial suspension of $1-5 \times 10^{6}$ cells $\mathrm{mL}^{-1}$. This initial suspension was diluted in RPMI, or RPMI + TW80, to obtain an inoculum of $1-5 \times 10^{3} \mathrm{CFU} \mathrm{mL}^{-1}$. For filamentous fungi, a spore suspension was prepared from pure culture with spores in SDA (A. fumigatus and S. brevicaulis) or MYC (dermatophytes) in sterile saline with one drop of TW20 added. The cell density was adjusted by the spore count and diluted in RPMI to obtain the adequate inoculum $\left(1-3 \times 10^{3} \mathrm{CFU} \mathrm{mL}^{-1}\right.$ for dermatophytes and 0.4-5 $\times 10^{4} \mathrm{CFU} \mathrm{mL}{ }^{-1}$ for A. fumigatus and S. brevicaulis). Voriconazole $\left(0.06-2 \mu \mathrm{g} \mathrm{mL}^{-1}\right)$ was used as a quality control with C. krusei ATCC ${ }^{\circledR}$ 6258; a MIC value of $0.5 \mathrm{mg} \mathrm{L}^{-1}$ was obtained. The results obtained were within the recommended limits defined by CLSI protocols. The plates were incubated aerobically at $35^{\circ} \mathrm{C}$ during $48 \mathrm{~h}$ for C. albicans and A. fumigatus, 3 days for $M$. furfur and at $25^{\circ} \mathrm{C}$ for 5-7 days for the dermatophytes.

MICs were determined as the lowest concentrations resulting in $100 \%$ growth inhibition, in comparison to the sample-free controls. The MLC was assessed by spreading $10 \mu \mathrm{L}$ of culture collected from wells showing no visible growth on SDA, or SAB+TW80, plates. The MLC was determined as the lowest concentration at which no colonies grew after $48 \mathrm{~h}$ incubation at $35^{\circ} \mathrm{C}$ for C. albicans and $A$. fumigatus, 3 days for $M$. furfur, and 7 days at $25^{\circ} \mathrm{C}$ for dermatophytes.

\subsection{Inhibition of 5-Lipoxygenase}

The evaluation of the 5-LOX inhibitory activity was based on the oxidation of linoleic acid to 13-hydroperoxylinoleic acid, as described in Kachmar et al. [48]. The absorbance of the reaction mixture containing $20 \mu \mathrm{L}$ of extract/compound, $200 \mu \mathrm{L}$ of phosphate buffer $(\mathrm{pH}=9), 20 \mu \mathrm{L}$ of soybean 5-LOX (100 U), and $20 \mu \mathrm{L}$ of linoleic acid (in ethanol) was determined at $234 \mathrm{~nm}$, at $37^{\circ} \mathrm{C}$, for 3 min, in a Multiskan ${ }^{\mathrm{TM}}$ GO microplate reader (Thermo Fisher Scientific Oy, Vantaa, Finland). LOX (Type V; EC 1.13.11.12) and linoleic acid were purchased from Sigma-Aldrich (St. Louis, MO, USA). Three independent assays were performed in triplicate and results were compared with those obtained upon treatment with quercetin (positive control), tested under the same conditions.

\subsection{Interference with RAW 264.7 Macrophages}

\subsubsection{RAW 264.7 Cells Culture and Viability}

Interference with the mitochondrial activity of RAW 264.7 macrophages was evaluated as in Ferreres et al. [49]. Murine macrophage ATCC ${ }^{\circledR}$ RAW 264.7 cells (LGC Standards S.L.U., Barcelona, Spain) were maintained in Dulbecco's Modified Eagle Medium (DMEM) supplemented with $10 \%$ heat-inactivated foetal bovine serum (FBS) and 1\% penicillin/streptomycin $\left(10000 \mathrm{U} \mathrm{mL}^{-1}\right)$, grown in a Toreuse model 2428 incubator (Saint Louis, MO, USA) at $37^{\circ} \mathrm{C}$, in a humidified atmosphere of $5 \%$ $\mathrm{CO}_{2}$. DMEM, FBS, and penicillin-streptomycin solution (Pen Strep) were from GIBCO, Invitrogen (Grand Island, NY, USA). RAW 264.7 cells were harvested by scraping and then suspended in flasks for growth.

Cellular mitochondrial activity was evaluated by the thiazolyl blue tetrazolium bromide (MTT; Sigma-Aldrich, St. Louis, MO, USA) reduction assay, using increasing concentrations of extract in DMEM. Cells were cultured in 96-well plates $\left(2.5 \times 10^{4}\right.$ cells well $\left.{ }^{-1}\right)$ and allowed to attach for $24 \mathrm{~h}$. After incubation with the hydroethanolic extract, MTT was added to each well, the plate being incubated for $90 \mathrm{~min}$ at $37^{\circ} \mathrm{C}$. Formazan crystals were then solubilized by the addition of a DMSO: 
isopropanol (3:1) mixture and quantified spectrophotometrically at $560 \mathrm{~nm}$ in a microplate reader. The results of cellular viability correspond to the mean \pm SEM of three independent experiments performed in triplicate, being expressed as a percentage of the untreated control cells.

\subsubsection{Determination of NO Levels}

Interference with LPS-activated NO levels was determined by measuring the nitrite accumulated in cell-free supernatants, via the Griess reaction. RAW 264.7 cells were cultured in 96-well plates $\left(3.5 \times 10^{4}\right.$ cells well $\left.^{-1}\right)$ for $24 \mathrm{~h}$ and then pre-treated with different concentrations of extract for $2 \mathrm{~h}$. LPS $\left(1 \mu \mathrm{g} \mathrm{mL}^{-1}\right)$ from E. coli (Sigma-Aldrich, St. Louis, MO, USA) was then added and the plates were further incubated for $22 \mathrm{~h}$. Absorbance was read at $540 \mathrm{~nm}$. The results correspond to the mean \pm SEM of three independent experiments performed in triplicate, being expressed as percentage of NO in cells exposed to LPS (positive control for NO production). Further details are as described in Ferreres et al. [49].

\subsection{HaCaT Cells Culture and Viability}

Human epidermal HaCaT keratinocytes were obtained from ATCC ${ }^{\circledR}$ and maintained in DMEM medium supplemented with $10 \%$ FBS and $1 \%$ penicillin/streptomycin $\left(10,000 \mathrm{U} \mathrm{mL}^{-1}\right)$, and grown as monolayer at $37^{\circ} \mathrm{C}$ in a $5 \% \mathrm{CO}_{2}$ atmosphere. After three days the culture was approximately $80 \%$ confluent, cells being harvested with trypsin-EDTA $0.25 \%$ solution (GIBCO, Invitrogen, Grand Island, NY, USA). Then the cells were subcultured in 96-well plates $\left(1.5 \times 10^{4}\right.$ cells well $\left.^{-1}\right)$, grown until $80 \%$ confluence, and subsequently exposed to the extract for $24 \mathrm{~h}$ at $37^{\circ} \mathrm{C}$. Interference with the mitochondrial activity was studied $24 \mathrm{~h}$ later by the MTT reduction assay as described in Gomes et al. [50]. Viable cells were calculated as a percentage of the negative control cells set at $100 \%$, results corresponding to the mean \pm SEM of three independent experiments performed in triplicate.

\subsection{Statistical Analysis}

Statistical analysis was performed using GraphPad Prism 6.01 Software (San Diego, CA, USA). Grubbs' test was used to detect and exclude outliers. Prior to the analysis, the data set was checked for normality of distribution using Shapiro-Wilk test, ensuring that all data follow a normal distribution. Unpaired student's $t$-test with Welch's correction was used to compare the existence of significant differences between treatment and control groups. Values of $p<0.05$ were considered statistically significant.

\section{Conclusions}

This paper describes for the first time the flavonoid profile of $S$. senegalensis, demonstrating the occurrence of myricitrin and quercetin derivatives, known for their antifungal and anti-inflammatory properties.

Furthermore, the antidermatophytic effects of a hydroethanolic extract obtained from the leaves of the plant, as well as the potential attenuating effects on the inflammatory response associated with dermatophytic infections, are also demonstrated. The extract was more active against the dermatophytes T. rubrum and E. floccosum, common causal agents of persisting dermatophytosis. As a result of the significant inhibitory effects against soybean 5-LOX, it seems evident that the hydroethanolic extract obtained from the leaves of $S$. senegalensis exerts an anti-inflammatory effect, at least in part, via the inhibition of the enzyme. It was also found that it did not interfere with the cellular viability of RAW 264.7 macrophages and NO levels, thus not hampering the potential fungicidal effects associated with the production of RNS. Relevantly, the current work indicates that the antidermatophytic and anti-inflammatory effects are achieved without interference with the cellular viability of the skin representative $\mathrm{HaCaT}$ cells.

We demonstrated that the leaf extract, obtained using cheap and non-hazard solvents, constitutes a source of potential crude drugs or bioactives, thus valorizing $S$. senegalensis. 
Author Contributions: Conceived and designed the experiments: E.P., P.V., and P.B.A.; Performed the experiments: N.G.M.G., A.P.O., and D.C.; Contributed reagents/materials/analytical tools: E.P., L.A., and P.B.A.; Wrote and revised the paper: N.G.M.G., A.P.O., D.M.P., P.V., E.P., and P.B.A.

Funding: This research received no external funding.

Acknowledgments: This work was supported by UID/QUI/50006/2019 with funding from FCT/MCTES through national funds, and by Programa de Cooperación Interreg V-A España - Portugal (POCTEP) 2014-2020 (project 0377_IBERPHENOL_6_E). This work was also supported by national funds through FCT - Fundação para Ciência e a Tecnologia, I.P., under the project CEECIND/03037/2017. Andreia P. Oliveira thanks to REQUIMTE for the research contract (DL57/2016/CP1346/CT0015). We are deeply indebted to Nelson Correia from Ilha Formosa (Guinea-Bissau) for sharing his knowledge on the traditional use of plants from Guinea-Bissau as well as his support on sample collection. We are also grateful to Pajaree Inthachup (Department of National Parks, Wildlife and Plant Conservation, Thailand) for the drawing of Salacia senegalensis (Lam.) DC.

Conflicts of Interest: The authors declare no conflict of interest.

\section{References}

1. Ferreres, F.; Gomes, N.G.; Valentao, P.; Pereira, D.M.; Gil-Izquierdo, A.; Araújo, L.; Silva, T.C.; Andrade, P.B. Leaves and stem bark from Allophylus africanus P. Beauv.: An approach to anti-inflammatory properties and characterization of their flavonoid profile. Food Chem. Toxicol. 2018, 118, 430-438. [CrossRef] [PubMed]

2. Mouho, D.G.; Oliveira, A.P.; Kodjo, C.G.; Valentão, P.; Ouattara, Z.A.; Bekro, Y.-A.; Andrade, P.B. Valorisation of Mangifera indica crop biomass residues. Ind. Crop. Prod. 2018, 124, 284-293. [CrossRef]

3. Mouho, D.G.; Oliveira, A.P.; Kodjo, C.G.; Valentão, P.; Gil-Izquierdo, A.; Andrade, P.B.; Ouattara, Z.A.; Bekro, Y.-A.; Ferreres, F. Chemical findings and in vitro biological studies to uphold the use of Ficus exasperata Vahl leaf and stem bark. Food Chem. Toxicol. 2018, 112, 134-144. [CrossRef]

4. Catarino, L.; Havik, P.J.; Romeiras, M.M. Medicinal plants of Guinea-Bissau: Therapeutic applications, ethnic diversity and knowledge transfer. J. Ethnopharmacol. 2016, 183, 71-94. [CrossRef] [PubMed]

5. Adumanya, O.C.U.; Uwakwe, A.A.; Essien, E.B. Essential oil composition (terpenes) of Salacia senegalensis Lam (DC) leaf. Br. J. Res. 2014, 1, 26-34.

6. Adumanya, O.C.U.; Obiloma, A.A.; Essien, E.B. Proximate analysis, vitamins and mineral composition of Salacia senegalensis Lam (DC) leaves. Open J. Res. 2015, 2, 92-105.

7. Balde, M.A.; Traore, M.S.; Diane, S.; Diallo, M.S.T.; Tounkara, T.M.; Camara, A.; Baldé, E.S.; Bah, F.; Ouedraogo, U.; Drame, H.; et al. Ethnobotanical survey of medicinal plants traditionally used in Low and Middle-Guinea for the treatment of skin diseases. J. Plant Sci. 2015, 3, 32-39.

8. Svetaz, L.; Zuljan, F.; Derita, M.; Petenatti, E.; Tamayo, G.; Cáceres, A.; Filho, V.C.; Giménez, A.; Pinzón, R.; Zacchino, S.A.; et al. Value of ethnomedical information for the discovery of plants with antifungal properties. A survey among seven Latin American countries. J. Ethnopharmacol. 2010, 127, 137-158. [CrossRef]

9. Martinez-Rossi, N.M.; Peres, N.T.; Rossi, A. Pathogenesis of dermatophytosis: Sensing the host tissue. Mycopathologia 2017, 182, 215-227. [CrossRef]

10. Havlickova, B.; Czaika, V.A.; Friedrich, M. Epidemiological trends in skin mycoses worldwide. Mycoses 2008, 51, 2-15. [CrossRef]

11. Vázquez-Torres, A.; Balish, E. Macrophages in resistance to candidiasis. Microbiol. Mol. Biol. Rev. 1997, 61, 170-192. [PubMed]

12. Hube, B.; Hay, R.; Brasch, J.; Veraldi, S.; Schaller, M. Dermatomycoses and inflammation: The adaptive balance between growth, damage, and survival. J. Mycol. Méd. 2015, 25, e44-e58. [CrossRef] [PubMed]

13. Bagnazari, M.; Saidi, M.; Chandregowda, M.M.; Prakash, H.S.; Nagaraja, G. Phyto-constituents, pharmacological properties and biotechnological approaches for conservation of the anti-diabetic functional food medicinal plant Salacia: A review note. Appl. Food Biotechnol. 2017, 4, 1-10.

14. Bagri, P.; Chester, K.; Khan, W.; Ahmad, S. Aspects of extraction and biological evaluation of naturally occurring sugar-mimicking sulfonium-ion and their synthetic analogues as potent $\alpha$-glucosidase inhibitors from Salacia: A review. RSC Adv. 2017, 7, 28152-28185. [CrossRef]

15. Jayawardena, M.; De Alwis, N.; Hettigoda, V.; Fernando, D. A double blind randomised placebo controlled cross over study of a herbal preparation containing Salacia reticulata in the treatment of type 2 diabetes. J. Ethnopharmacol. 2005, 97, 215-218. [CrossRef] [PubMed] 
16. Adumanya, O.C.U. Carotenoids, phenolics, hydroxycinnamic acids and tannin composition of Salacia senegalensis (Lam) DC leaves. Nat. Prod. Chem. Res. 2016, 5, 1.

17. Markham, K.R.; Bloor, S.J. Analysis and identification of flavonoids. In The Flavonoids - Advances in Research, 1st ed.; Harborne, J.B., Mabry, T.J., Eds.; Chapman and Hall: London, UK, 1998; pp. 19-134.

18. Essien, A.D.; Akuodor, G.C.; Ajoku, G.A.; Megwas, A.U.; Anele, D.O.; Ezeunala, M.N.; Okezie, A.O. Antimicrobial and toxicological evaluation of ethanol leaf extract of Salacia lehmbachii. Interdiscip. Toxicol. 2017, 10, 163-167. [CrossRef]

19. Kannaiyan, M.; Manuel, V.N.; Raja, V.; Thambidurai, P.; Mickymaray, S.; Nooruddin, T. Antimicrobial activity of the ethanolic and aqueous extracts of Salacia chinensis Linn. against human pathogens. Asian Pac. J. Trop. Dis. 2012, 2, S416-S420. [CrossRef]

20. Subhasree, N.; Shivakumar, S.; Sandhiya, A.A.; Dubey, G.P. Vitro assessment of antioxidant and antibacterial activities of Salacia species - A comparative study. Int. J. Pharm. Pharm. Sci. 2013, 5, 279-282.

21. Rodrigues, V.G.; Duarte, L.P.; Silva, R.R.; Silva, G.D.F.; Mercadante-Simões, M.O.; Takahashi, J.A.; Matildes, B.L.G.; Fonseca, T.H.S.; Gomes, M.A.; Filho, S.A.V. Salacia crassifolia (Celastraceae): CHEMICAL CONSTITUENTS AND ANTIMICROBIAL ACTIVITY. Química Nova 2015, 38, 237-242. [CrossRef]

22. Gupta, A.K.; Foley, K.A.; Versteeg, S.G. New antifungal agents and new formulations against dermatophytes. Mycopathologia 2017, 182, 127-141. [CrossRef] [PubMed]

23. Lopes, G.; Pinto, E.; Salgueiro, L. Natural products: An alternative to conventional therapy for dermatophytosis? Mycopathologia 2017, 182, 143-167. [CrossRef] [PubMed]

24. Daglia, M. Polyphenols as antimicrobial agents. Curr. Opin. Biotechnol. 2012, 23, 174-181. [CrossRef] [PubMed]

25. Tracanna, M.I.; Fortuna, A.M.; Cardenas, A.V.C.; Marr, A.K.; McMaster, W.R.; Gómez-Velasco, A.; Sánchez-Arreola, E.; Hernández, L.R.; Bach, H. Anti-leishmanial, anti-inflammatory and antimicrobial activities of phenolic derivatives from Tibouchina paratropica. Phytother. Res. 2015, 29, 393-397. [CrossRef]

26. Ghani, S.B.A.; Weaver, L.; Zidan, Z.H.; Ali, H.M.; Keevil, C.W.; Brown, R.C. Microwave-assisted synthesis ant antimicrobial activities of flavonoid derivatives. Bioorg. Med. Chem. Lett. 2008, 18, 518-522. [CrossRef]

27. Romani, L. Immunity to fungal infections. Nat. Rev. Immunol. 2011, 11, 275-288. [CrossRef]

28. Andoh, T.; Haza, S.; Saito, A.; Kuraishi, Y. Involvement of leukotriene $\mathrm{B}_{4}$ in spontaneous itch-related behaviour in NC mice with atopic dermatitis-like skin lesions. Exp. Dermatol. 2011, 20, 894-898. [CrossRef] [PubMed]

29. Krieg, P.; Fürstenberger, G. The role of lipoxygenases in epidermis. Biochim. Biophys. Acta BBA Mol. Cell Biol. Lipids 2014, 1841, 390-400. [CrossRef] [PubMed]

30. Gupta, A.K.; Nicol, K.; Batra, R. Role of Antifungal Agents in the Treatment of Seborrheic Dermatitis. Am. J. Clin. Dermatol. 2004, 5, 417-422. [CrossRef] [PubMed]

31. Dixon, R.A.F.; Diehl, R.E.; Opas, E.; Rands, E.; Vickers, P.J.; Evans, J.F.; Gillard, J.W.; Miller, D.K. Requirement of a 5-lipoxygenase-activating protein for leukotriene synthesis. Nature 1990, 343, 282-284. [CrossRef]

32. Percival, M.D. Human 5-lipoxygenase contains an essential iron. J. Biol. Chem. 1991, 266, $10058-10061$. [PubMed]

33. Ribeiro, D.; Freitas, M.; Tomé, S.M.; Silva, A.M.; Porto, G.; Cabrita, E.J.; Marques, M.M.B.; Fernandes, E. Inhibition of LOX by flavonoids: a structure-activity relationship study. Eur. J. Med. Chem. 2014, 72, 137-145. [CrossRef] [PubMed]

34. Mascolo, N.; Pinto, A.; Capasso, F. Flavonoids, leucocyte migration and eicosanoids. J. Pharm. Pharmacol. 1998, 40, 293-295. [CrossRef]

35. Winekenstädde, D.; Angelis, A.; Waltenberger, B.; Schwaiger, S.; Tchoumtchoua, J.; König, S.; Werz, O.; Aligiannis, N.; Skaltsounis, A.-L.; Stuppner, H. Phytochemical Profile of the Aerial Parts of Sedum sediforme and Anti-inflammatory Activity of Myricitrin. Nat. Prod. Commun. 2015, 10, 83-88. [CrossRef] [PubMed]

36. Kim, M.Y.; Kim, Y.C.; Chung, S.K. Identification and in vitro biological activities of flavonols in garlic leaf and shoot: Inhibition of soybean lipoxygenase and hyaluronidase activities and scavenging of free radicals. J. Sci. Food Agric. 2005, 85, 633-640. [CrossRef]

37. Gomes, A.; Fernandes, E.; Lima, J.; Mira, L.; Corvo, M.L. Molecular Mechanisms of Anti-Inflammatory Activity Mediated by Flavonoids. Curr. Med. Chem. 2008, 15, 1586-1605. [CrossRef] [PubMed]

38. Sadik, C.D.; Sies, H.; Schewe, T. Inhibition of 15-lipoxygenases by flavonoids: structure-activity relations and mode of action. Biochem. Pharmacol. 2003, 65, 773-781. [CrossRef] 
39. Noverr, M.C.; Toews, G.B.; Huffnagle, G.B. Production of Prostaglandins and Leukotrienes by Pathogenic Fungi. Infect. Immun. 2002, 70, 400-402. [CrossRef]

40. Werz, O. Inhibition of 5-Lipoxygenase Product Synthesis by Natural Compounds of Plant Origin. Planta Med. 2007, 73, 1331-1357. [CrossRef]

41. Baltazar, L.M.; Krausz, A.E.; Souza, A.C.O.; Adler, B.L.; Landriscina, A.; Musaev, T.; Nosanchuk, J.D.; Friedman, A.J. Trichophyton rubrum is Inhibited by Free and Nanoparticle Encapsulated Curcumin by Induction of Nitrosative Stress after Photodynamic Activation. PLoS ONE 2015, 10, e0120179. [CrossRef]

42. Barker, J.; Griffiths, C.; Mitra, R.; Dixit, V.; Nickoloff, B.; Griffiths, C. Keratinocytes as initiators of inflammation. Lancet 1991, 337, 211-214. [CrossRef]

43. Hesselink, J.M.K.; Kopsky, D.J.; Bhaskar, A.K. Skin matters! The role of keratinocytes in nociception: A rational argument for the development of topical analgesics. J. Pain. Res. 2017, 10, 1-8. [CrossRef] [PubMed]

44. Wiegand, C.; Hipler, U.-C. Evaluation of Biocompatibility and Cytotoxicity Using Keratinocyte and Fibroblast Cultures. Ski. Pharmacol. Physiol. 2009, 22, 74-82. [CrossRef] [PubMed]

45. John, H.R.; Barbara, D.A.; David, A. Reference Method For Broth Dilution Antifungal Susceptibility Testing of Yeasts, 3rd ed.; Clinical and Laboratory Standards Institute: Wayne, PA, USA, 2008.

46. John, H.R.; Barbara, D.A.; David, A. Reference Methods For Broth Dilution Antifungal Susceptibility Testing of Filamentous Fungi, 2nd ed.; Clinical and Laboratory Standards Institute: Wayne, PA, USA, 2008.

47. Jean, B.P.; Franklin, R.C.; Patricia, A.B. Methods for Dilution Antimicrobial Susceptibility Tests for Bacteria That Grow Aerobically, 10th ed.; Clinical and Laboratory Standards Institute: Wayne, PA, USA, 2015.

48. Kachmar, M.R.; Oliveira, A.P.; Valentão, P.; Gil-Izquierdo, A.; Domínguez-Perles, R.; Ouahbi, A.; Badaoui, K.E.; Andrade, P.B.; Ferreres, F. HPLC-DAD-ESI/MS ${ }^{\mathrm{n}}$ phenolic profile and in vitro biological potential of Centarium erythraea Rafn aqueous extract. Food Chem. 2019, 278, 424-433. [CrossRef] [PubMed]

49. Ferreres, F.; Duangsrisai, S.; Gomes, N.G.; Suksungworn, R.; Pereira, D.M.; Gil-Izquierdo, A.; Valentão, P.; Choowongkomon, K.; Andrade, P.B. Anti-inflammatory properties of the stem bark from the herbal drug Vitex peduncularis Wall. ex Schauer and characterization of its polyphenolic profile. Food Chem. Toxicol. 2017, 106, 8-16. [CrossRef] [PubMed]

50. Gomes, N.G.M.; Fernandes, F.; Madureira-Carvalho, Á.; Valentão, P.; Lobo-Da-Cunha, A.; Calado, G.; Andrade, P.B. Profiling of Heterobranchia Sea Slugs from Portuguese Coastal Waters as Producers of Anti-Cancer and Anti-Inflammatory Agents. Molecules 2018, 23, 1027. [CrossRef] [PubMed]

Sample Availability: Samples of the compounds 1, 3, 6 and 7 are available from the authors.

(C) 2019 by the authors. Licensee MDPI, Basel, Switzerland. This article is an open access article distributed under the terms and conditions of the Creative Commons Attribution (CC BY) license (http://creativecommons.org/licenses/by/4.0/). 